Halaman : $193-198$

\title{
PROFIL LABORATORIUM IPA/BIOLOGI SMP SWASTA DI KOTA PEKANBARU
}

\section{LABORATORY PROFILE OF SCIENCE/BIOLOGY PRIVATE JUNIOR HIGH SCHOOL IN PEKANBARU CITY}

\author{
Mellisa ${ }^{1^{*}}$ \\ ${ }^{1}$ Program Studi Pendidikan Biologi, Fakultas Keguruan dan Ilmu Pendidikan, Univesitas Islam Riau \\ Email: mellisabio@edu.uir.ac.id
}

\begin{abstract}
ABSTRAK
Penelitian ini adalah metode survey. Metode survei adalah penilitian yang dilakukan untuk mengumpulkan informasi yang dilakukan dengan cara menyusun daftar pertanyaan yang diajukan pada responden. Dalam penelitian survei digunakan untuk meneliti segala suatu kelompok atau perilaku individu. Penggalian data dapat melalui lembar observasi dan wawancara. Pengumpulan data menggunakan Lembar observasi berdasarkan Permendiknas No.24 tahun 2007. Hasil Profil laboratorium SMP Swasta di Kota Pekanbaru didapatkan rata-rata dalam kriteria lengkap berdasarkan kelengkapan sarana dan prasarana laboratorium IPA/Biologi di 5 SMP Swasta di Kota Pekanbaru. Pada SMP Swasta Dwi Sejahtera memperoleh skor sebesar55.88\% (Lengkap). Selanjutnya SMP Swasta Bhayangkari persentase diperoleh sebesar 77.4\% (Sangat Lengkap). Pada SMP Swasta Yabri Terpadu persentase diperoleh sebesar $53.58 \%$ (Lengkap) dan SMP Swasta Teknologi persentase diperoleh sebesar 1.42\% (Sangat Tidak Lengkap), Selanjutnya SMP Swasta Insan Utama persentase diperoleh sebesar54\% (Lengkap).
\end{abstract}

Kata kunci : Profil Pengelola, Laboratorium biologi, SMP Swasta Pekanbaru

\begin{abstract}
The method of this research is a survey which conducted to collect information carried out by compiling a list of questions submitted to respondents. Commonly, survey research is used to examine all a group or individual behavior. Collecting the data using observation and interview sheets. Data collection uses observation sheets based on Minister of National Education Regulation No.24 of 2007. The private junior high schools In Pekanbaru city, laboratory profile resulted complete criteria on average based on the completeness of science and biology laboratory facilities and infrastructure at five private junior high schools. At Private Middle School of Dwi Sejahtera obtained a score of $55.88 \%$ (Complete). Furthermore, the percentage of Private Middle School of Bhayangkari was obtained at 77.4\% (Very Complete). At Private Junior High School of Yabri, the percentage obtained was 53.58\% (Complete) and Private Junior High School of Technology obtained percentage of $1.42 \%$ (Very Incomplete), then Private Junior High School of Insan Utama obtained percentage of 54\% (Complete).
\end{abstract}

Keywords: Laboratory Profile of Science / Biology, Teacher Competence of Laboratory 
Halaman : $193-198$

\section{PENDAHULUAN}

Pendidikan dapat diartikan sebagai sebuah proses dengan metode-metode tertentu sehingga orang memperoleh pengetahuan, pemahaman, dan cara bertingkah laku yang sesuai dengan kebutuhan (Dalyono, 2010: 4). Guru dalam era teknologi informasi dan komunikasi sekarang ini bukan hanya sekedar mengajar melainkan harus menjadi menejer belajar. Hal tersebut mengandung arti, setiap guru diharapkan mampu menciptakan kondisi belajar yang menantang kreativitas dan aktivitas siswa, memotivasi siswa, menggunakan multimedia, multimetode, dan multisumber agar mencapai tujuan pembelajaran yang diharapkan.

Berdasarkan Peraturan Pemerintah Nomor 19 Tahun 2005 tentang Standar Nasional Pendidikanpasal 42 ayat 1 dinyatakan bahwa, setiap satuan pendidikan wajib memiliki sarana yang meliputi perabot, peralatan pendidikan, media pendidikan, buku dan sumber belajar lainnya, bahan habis pakai, serta perlengkapan lain yang diperlukan untuk menunjang proses pembelajaran yang teratur dan berkelanjutan. Alat dan sumber, walaupun fungsinya sebagai alat bantu, akan tetapi memiliki peran yang tidak kalah pentingnya.

Keberadaan laboratorium sains di sekolah menengah sudah merupakan suatu keharusan pada pendidikan sains moderen. Sains diangap mengandung 3 aspek, yaitu produk, proses, dan sikap. Dalam perkembangannya, kata "laboratorium" mempertahankan arti aslinya, yaitu "tempat bekerja", tetapi khusus untuk keperluan penelitian ilmiah. Ketika sains dan teknologi berkembang pesat dan menjadi salah satu mata pelajaran penting dalam kurikulum, banyak pendidik/pengajar sains merasa perlu mengadakan ruang tempat siswa melakukan kegiatan-kegiatan yang berkaitan dengan sains. Para pendidik berpandangan bahwa sains ilmu yang empiris, yaitu ilmu yang didasari atas penagmatan dan eksperimentasi (percobaan) adalah bagian integral sains. Laboratorium yang digunakan untuk kegiatan ini disebut laboratorium sains sekolah (Kertiasa, 2006: 1).

Berdasarkan Permendiknas No.24 tahun 2007 kriteria laboratorium Biologi yaitu : 1) ruang laboratorium biologi berfungsi sebagai tempat berlangsungnya kegiatan pembelajaran biologi secara praktek yang memerlukan peralatan khusus, 2) ruang laboratorium biologi dapat menampung minimum satu rombongan belajar, 3) rasio minimum ruang laboratorium biologi $2,4 \mathrm{~m}^{2}$ / peserta didik. Untuk rombongan belajar dengan peserta didik kurang dari 20 orang, luas minimum ruang laboratorium $48 \mathrm{~m}^{2}$ termasuk luas ruang penyimpanan dan persiapan $18 \mathrm{~m}^{2}$ Lebar minimum ruang laboratorium biologi $5 \mathrm{~m}$, 4) ruang laboratorium biologi memiliki fasilitas yang memungkinkan pencahayaan memadai untuk membaca buku dan mengamati obyek percobaan, 5) ruang laboratorium biologi dilengkapi sarana

Mastika (2014) dalam jurnalnya, menyatakan bahwa kondisi daya dukung laboratorium IPA/Biologi yang ada di delapan sekolah negeri kota Denpasar menunjukkan bahwa kondisinya belum memenuhi standar minimal $100 \%$ yang telah ditetapkan yakni: 1) Fasilitas daya dukung sarana prasarana yang ada di ruang laboratorium IPA/Biologi yang ada di delapan sekolah SMA Negeri Kota Denpasar belum memenuhi standar minimal $100 \% \quad(80,56 \%)$. Demikian pula dari hasil penelitian yang dilakukan Fithri (2013), menunjukkan bahwa sarana dan prasarana laboratorium IPA di SMP Negeri 1 Kajoran Kabupaten Magelang sebagai pendukung kegiatan IPA Fisika termasuk kedalam kategori yang sesuai sekali (SS) dimana memiliki presentase kesesuaian dengan standar keseluruhan Permendiknas No.24 Tahun 2007 tentang sarana dan prasarana laboratorium IPA dengan hasil (86,37\%).

Hasil survey rata-rata SMP Swasta di kota Pekanbaru tidak memiliki laboran, teknisi labor dan daya dukung laboratorium IPA/Biologi sehingga pengelola atau kepala laboratorium IPA kewalahan dalam mengurus laboratorium IPA, administrasi laboratorium masih ada yang belum lengkap, sarana dan prasaran yang tidak lengkap.

Berdasarkan latar belakang yang di kemukakan di atas maka peneliti melakukan penelitian dengan judul "Profil Laboratorium IPA di SMP Swasta di Kota Pekanbaru". 
Halaman : $193-198$

\section{METODE PENELITIAN}

Jenis Penelitian ini merupakan penelitian kuantitatif dengan analisis deskriptif. Populasi pada penelitian ini adalah guru (IPA) di 5 SMP Swastakota Pekanbaru. Waktu pelaksanaan dimulai pada bulan November 2017 - Januari 2018.

Teknik pengumpulan data yang meliputi : (1) Observasi merupakan suatu kegiatan mendapatkan informasi yang diperlukan untuk menyajikan gambaran riil suatu peristiwa atau kejadian untuk menjawab pertanyaan penelitian, untuk membantu mengerti perilaku manusia dan untuk evaluasi yaitu melakukan pengukuran terhadap aspek tertentu melakukan umpan balik terhadap pengukuran tersebut. Hasil observasi berupa aktivitas, kejadian, peristiwa, objek, kondisi atau suasana tertentu (Sujarweni, 2014: 32). 2) Wawancara adalah proses memperoleh penjelasan untuk mengumpulkan informasi dengan menggunakan cara tanya jawab bisa sambil bertatap muka ataupun tanpa tatap muka yaitu melalui media telekomunikasi antara pewawancara dengan orang yang diwawancarai, dengan atau tanpa menggunakan pedoman. Pada hakikatnya wawancara merupakan kegiatan untuk memperoleh informasi secara mendalam tentang sebuah isu yang diangkat dalam penelitian. Atau merupakan proses pembuktian terhadap informasi atau keterangan yang telah diperoleh lewat teknik yang lain sebelumnya (Sujarweni, 2014: 31). 3) Dokumentasi, yaitu pengumpulan data diperlukan seperangkat alat atau instrument yang memandu, untuk pengambilan data-data dokumen (Sujarweni, 2014: 101).

Pengambilan data profil laboratorium IPA/Biologi dilakukan dengan pengamatan langsung (observasi) di laboratorium dan lembar observasi (lembar cheklist) yang terdiri dari 49 soal. Teknik analisis data untuk profil laboratorium IPA/biologi dihitung dengan penentuan nilai yang terdiri dari lima kategori yaitu

Tabel 1. Interval Profil Laboratorium IPA/Biologi

\begin{tabular}{cc}
\hline INTERVAL & KETERANGAN \\
\hline $75 \%-100 \%$ & Sangat Lengkap \\
$50 \%-74 \%$ & Lengkap \\
$25 \%-49 \%$ & Tidak lengkap \\
$0 \%-24 \%$ & Sangat Tidak Lengkap \\
\hline
\end{tabular}

Sumber: Modifikasi Peneliti dari Sudijono (2012)

\section{HASIL PENELITIAN}

Tabel 2 adalah Analisis data kelengkapan sarana dan prasarana laboratorium IPA/Biologi di 5 SMP Swasta di Kota Pekanbaru. Pada SMP Swasta Dwi Sejahtera memperoleh skor sebesar55.88\% (Lengkap). Selanjutnya SMP Swasta Bhayangkari persentase diperoleh sebesar77.4\% (Sangat Lengkap). Pada SMP Swasta Yabri Terpadu persentase diperoleh sebesar 53.58\% (Lengkap) dan SMP Swasta Teknologi persentase diperoleh sebesar $1.42 \%$ (Sangat Tidak Lengkap)Selanjutnya SMP Swasta Insan Utama persentase diperoleh sebesar 54\% (Lengkap).

Tabel 2. Kelengkapan alat dan Bahan laboratorium IPA/Biologi SMP Swasta di Kota Pekanbaru.

\begin{tabular}{crlcccl}
\hline \multirow{2}{*}{ No } & \multirow{2}{*}{ Indikator (\%) } & \multicolumn{5}{c}{ Sekolah } \\
\cline { 3 - 7 } & & \multicolumn{1}{c}{$\mathrm{A}$} & \multicolumn{1}{c}{$\mathrm{B}$} & $\mathrm{C}$ & \multicolumn{1}{c}{$\mathrm{D}$} & \multicolumn{1}{c}{$\mathrm{E}$} \\
\hline 1 & Perabot Lab. & $65.21(\mathrm{~L})$ & $89.5(\mathrm{SL})$ & $51.06(\mathrm{~L})$ & $2.38(\mathrm{STL})$ & $75(\mathrm{SL})$ \\
2 & Peralatan Lab. & $19.81(\mathrm{STL})$ & $58.5(\mathrm{~L})$ & $9.43(\mathrm{STL})$ & $3.3(\mathrm{STL})$ & $17.92(\mathrm{STL})$ \\
3 & Media Lab. & $100(\mathrm{SL})$ & $100(\mathrm{SL})$ & $100(\mathrm{SL})$ & $0(\mathrm{STL})$ & $100(\mathrm{SL})$ \\
4 & Perlengkapan Lain & $38.48(\mathrm{TL})$ & $61.5(\mathrm{~L})$ & $53.84(\mathrm{~L})$ & $0(\mathrm{STL})$ & $23.07(\mathrm{STL})$ \\
\hline Rata-rata (Kriteia) & $55.88(\mathrm{~L})$ & $77.4(\mathrm{SL})$ & $53.58(\mathrm{~L})$ & $1.42(\mathrm{STL})$ & $54(\mathrm{~L})$ \\
\hline
\end{tabular}

\section{PEMBAHASAN}

SMP Swasta Dwi Sejahtera

Berdasarkan Hasil Tabel 2 menunjukkan bahwa Sekolah SMP Swasta Dwi Sejahtera pada indikator perabotan laboratorium pada kategori lengkap (65.21\%), peralatan laboratorium dikategorikan Sangat tidak lengkap (19,81\%), Media laboratorium dikategorikan Sangat lengkap (100\%),sedangkan pada indikator perlengkapan lain pada kategori tidak legkap (38,48\%). Hasil keseluruhan rata-rata persentasi kelengkapan alat 
dan bahan laboratorium di SMP Swasta Dwi Sejahtera dikategorikan lengkap (55,88\%).

Berdasarkan Hasil Observasi dapat dilihat bahwa kelengkapan perabotan memiliki kursi, meja dan lemari dengan kondisi bagus, kuat dan aman, tetapi tidak memiliki bak cuci. Sedangkan pada perlengkapan laboratorium mempunyai peralatan yang masih dikategorikan bagus dan kondisi yang baik hanya saja tidak sesuai denga jumlah ideal yang harus dimiliki pada kelengkapan alat dan bahan pada laboratorium. Sedangkan pada media pendidikan memiliki kondisi yang baik, dan perlengkapan lain laboratorium memiliki alat pemadam kebakaran, peralatan P3K, tempat sampah jam didinding, tetapi hanya saja soket listrik hanya memiliki satu saja sehingga tidak sesuai dengan standar untuk kelompok pratikum.

Berdasarkan Hasil Observasi luas ruang keseluruhan laboratorium di SMP Swata Dwi Sejahtera $56 \mathrm{~m}^{2}$ dikategorikan sangat sesuai dengan Permendiknas,dan kapasitas rata-rata siswa satu kelas menggunakan ruang labor antar 20-27 orang dan cukup untuk digunakan sebagai ruang pratikum. Laboratorium memiliki pencahayaan yang memadai, tetapi tidak memiliki sumber air yang bersih.

Hasil Iwawancara dapat disimpulkan kurang kondusifnya suatu ruangan laboratorium untuk dijadikan proses praktikum, hal tersebut berkaitan dengan sarana dan prasarana yang sangat kurangnya. Pengurus laboratorium sudah ada namun belum memiliki teknisi labor.

SMP Swasta Bhayangkari

Berdasarkan Hasil Menunjukkan bahwa Sekolah SMP Swasta Bhayangkari pada indikator perabotan laboratorium pada kategori sangat lengkap (89.5\%), peralatan laboratorium dikategorikan lengkap (58,49\%), Media laboratorium dikategorikan Sangat lengkap (100\%), sedangkan pada indikator perlengkapan lain pada kategori tidak legkap (61,53\%). Hasil keseluruhan rata-rata persentasi kelengkapan alat dan bahan laboratorium di SMP Swasta Bahyangkari dikategorikan lengkap (61,53\%).

Berdasarkan Hasil Observasi dapat dilihat bahwa kelengkapan perabotan memiliki kursi, meja dan lemari dengan kondisi bagus, kuat dan aman, dan juga memiliki bak cuci sesuai denga standar. Sedangkan pada perlengkapan laboratorium mempunyai peralatan yang masih dikategorikan bagus dan kondisi yang baik hanya saja belum sesuai dengan jumlah ideal yang harus dimiliki pada kelengkapan alat dan bahan pada laboratorium. Sedangkan pada media pendidikan memiliki kondisi yang baik, dan perlengkapan lain laboratorium memiliki alat pemadam kebakaran, peralatan P3K, tempat sampah jam didinding, tetapi hanya saja soket listrik hanya memiliki 4 saja sehingga tidak sesuai dengan standar untuk kelompok pratikum.

Berdasarkan Hasil Observasi luas ruang keseluruhan laboratorium di SMP Swata Bhayangkari $49 \mathrm{~m}^{2}$ dikategorikan sangat sesuai dengan Permendiknas,dan kapasitas rata-rata siswa satu kelas menggunakan ruang labor antar 20-27 orang dan sangat cukup untuk digunakan sebagai ruang pratikum. Laboratorium memiliki pencahayaan yang kurang memadai, dan sudah memiliki sumber air yang bersih.

Hasil wawancara dapat disimpulkan bahwa ruangan laboratorium yaitu cukup kondusifnya untuk dijadikan proses praktikum, berkaitan dengan sarana dan prasarana yaitu sangat cukup alat dan bahan yang ada di laboratorium meskipun masih dikategorikan kurang dan pengurus laboratorium sudah ada namun tidak adanya teknisi laboran.

\section{SMP Swasta Yabri Terpadu}

Berdasarkan Hasil Menunjukkan bahwa Sekolah SMP Swasta Yabri Terpadu pada indikator perabotan laboratorium pada kategori lengkap (51.06\%), peralatan laboratorium dikategorikan sangat tidak lengkap (9,43\%), Media laboratorium dikategorikan Sangat lengkap (100\%), sedangkan pada indikator perlengkapan lain pada kategori lengkap (53.84\%). Hasil keseluruhan rata-rata persentasi kelengkapan alat dan bahan laboratorium di SMP Swasta Yabri Terpadu dikategorikan lengkap (53.58\%).

Berdasarkan hasil observasi masih banyak peralatan laboratorium yang belum dimiliki sehingga untuk proses pelaksanaan pratikum masih dikategorikan sangat tidak lengkap. Luas keseluruhan ruangan $36 \mathrm{~m}^{2}$ dan masih dikategorikan belum sesuai dengan Permendiknas. Ruang penyimpanan tidak ada, ruang persiapan 
tidak ada, rata-rata siswa sekitar 29 orang dalam menggunakan laboratorium, sumber air bersih dan pencahayaan memadai.

Berdasarkan wawancara dengan pengelola laboaratorium belum pernah mengikuti pelatihan laboran sehingga belum menunjukkan komitmen terhadap pengelolaan laboratorium. Selain itu kendala yang dihadapi yaitu masih dipakainya laboratorium sebagai proses belajar mengajar dan belum lengkapnya sarana dan prasarana yang memadai dikarenakan pengajuan sarana, alat dan bahan yang masih tertunda diyayasan. Ruangan labor masih digunakan dalam proses belajar mengajar.

\section{SMP Swasta Teknologi}

Hasil kelengkapan alat dan bahan laboratorium disekolah SMP Swasta Teknologi dikategorikan sangat tidak lengkap dengan ratarata $1.42 \%$. Laboratorium disekolah SMP Swasta Terknologi masih sangat tidak lengkap, dalam hal perabotan laboratorim (2.38\%), peralatan laboratorium (3.30\%), Media pendidikan dan peralatan lain.

Bedasarkan hasil observasi laboeratorium hanya memiliki seperti lemari alat, thermometer gelas ukur, gelas kimia, mikroskop. Alat dan bahan laboratorium lain sangat minim dikarenakan sekolah tersebut masih dikategorikan sangat baru berdiri. Berdasarkan hasil wawancara dengan pengelola labor bahwa untuk pelaksanaan pratikum dilakukan didalam ruangan kelas karena tidak ada ruang laboartorium.

\section{SMP Swasta Insan Utama}

Berdasarkan Hasil Menunjukkan bahwa Sekolah SMP Swasta Insan Utama pada indikator perabotan laboratorium pada kategori lengkap (75\%), peralatan laboratorium dikategorikan sangat tidak lengkap (17.92\%), Media laboratorium dikategorikan Sangat lengkap (100\%), sedangkan pada indikator perlengkapan lain pada kategori sangat lengkap (23.07\%). Hasil keseluruhan ratarata persentasi kelengkapan alat dan bahan laboratorium di SMP Swasta Insan Utama dikategorikan lengkap (54\%).

Observasi didapatkan bahwa ruang laboratorium berkisar antara $30 \mathrm{~m}^{2}$ dimana tidak terdapat ruang penyimpanan dan ruang persiapan.
Sedangakan jumlah siswa dalam satu kelas terdiri dari 15-20 siswa yang cukup untuk menanpung ketika pelaksanaan pratikum. Ruang laboratorium tidak tersedianya air bersih dan pencahayaan yang memadai. Peralatan laboratorium gambar model tubuh manusia sangat baik dan jelas tetapi dalam jumlah yang masih sedikit. Perabotan laboratorium dalam bentuk kursi dan meja dalm kondisi kuat dan aman.

Berdasarkan hasil wawanvara dengan pengelola labor bahwa sarana dan prasarana tidak dikhususkan mata pelajaran biologi, tetapi lebih keseluruh mata pelajaran IPA. Pengelola labor sudah mengikuti pelatihan sebagai pengelola labor pada tahun 2006. Sarana dan prasarana labor masih sangat kurang untuk pelaksanaan pratikum, dan pengelola labor mencoba untuk melakukan cara lain agar bias melakukan pratikum.selain itu ruang laboratorium juga dijadikan sebagai ruang belajar.

\section{KESIMPULAN}

Berdasarkan hasil penelitian, dapat disimpulkan bahwa Profil laboratorium rata-rata dalam kriteria lengkap. Kelengkapan sarana dan prasarana laboratorium IPA/Biologi di 5 SMP Swasta di Kota Pekanbaru. Pada SMP Swasta Dwi Sejahtera memperoleh skor sebesar55.88\% (Lengkap). Selanjutnya SMP Swasta Bhayangkari persentase diperoleh sebesar 77.4\% (Sangat Lengkap). Pada SMP Swasta Yabri Terpadu persentase diperoleh sebesar $53.58 \%$ (Lengkap) dan SMP Swasta Teknologi persentase diperoleh sebesar $1.42 \%$ (Sangat Tidak Lengkap)Selanjutnya SMP Swasta Insan Utama persentase diperoleh sebesar54\% (Lengkap).

\section{DAFTAR PUSTAKA}

Dalyono. 2010. Psikologi Pendidikan. Rineka Cipta: Jakarta.

Kertiasa, N. 2006. Laboratorium Sekolah \& Pengelolannya. Pudak Scientific: Bandung.

Mastika, N., Adnyana, P., dan Setiawan, G.2014. "Analisis Standarisasi Laboratorium Biologi Dalam Proses Pembelajaran Di SMA Negeri Kota Denpasar". e-journal Program pascasarjana Universitas pendidikan Ganesha Program Studi IPA. Volume 4 tahun 2014. Universitas Pendidikan 
Halaman : $193-198$

Ganesha: Singaraja. http:// pasca.undiksha.ac.id. Diakses 24 juni 2014.08:23 wib.

Peraturan Pemerintah. Nomor 19 Tahun 2005. Standar Nasional Pendidikan. Jakarta.

Permendiknas. Nomor 19 Tahun 2007. Standar pengelolaan Pendidikan. Jakarta

Permendiknas. Nomor 24 Tahun 2007. Standar Sarana dan Prasarana. Jakarta.

Permendiknas. Nomor 26 Tahun 2008. Standar Tenaga Laboratorium Sekolah/Madrasah. Jakarta

Sanjaya, Wina. 2006. Strategi Pembelajaran Berorientasi Standar Proses Pendidikan. Kencana Prenada Media Grup: Jakarta.

Sudijono, Anas. 2008. Pengantar Statistika Pendidikan. Raja Grafindo Persada: Jakarta.

Sujarweni. 2014. Metodologi Penelitian. Pustaka Baru Press: Yogyakarta. 